\title{
Study of Lead Content in Ayurvedic and Homeopathic Medicines Commonly Used for the Treatment of Cold, Cough \& Body Aches
}

\author{
Dr. Preeti Mangala \\ Department of Chemistry \& Biochemistry, Jyoti Nivas College Autonomous, Bangalore- 560 095, India
}

\begin{abstract}
:
Medicine- The life line of mankind!
Medicine is the art and science of healing. It encompasses a range of health care practices evolved to maintain and restore health by the prevention and treatment of illness. Some of the kinds of treatment are ayurveda and homeopathy. Medicines are consumed for the treatment of various ailments. The most widespread ailments are cold, cough and body aches for which people generally go for ayurvedic and homeopathy medicines especially in case of children and infants. Lead (Pb) may be present in small but appreciable quantities in medicines due to contamination during packaging through soldering, addition of lead compounds as colouring agent and preservatives etc. Lead has harmful effects in humans especially in infants. Lead on entry into the human body, gets absorbed and distributed to all the tissues and finally gets accumulated in the bones. Lead crosses the blood-brain barrier in infants and damages the Central Nervous System (CNS). The overall result shows undesirably high lead content in medicinal samples of aforesaid categories.
\end{abstract}

Keywords: Lead, Ayurvedic, Homeopathy, Central Nervous System.

\section{Introduction}

Lead is a naturally occurring metal having versatile use in building construction, lead acid batteries, bullets and shot, weights, and is part of solder, pewter, fusible alloys and radiation shields. However, even small amounts of lead can be hazardous to our health ${ }^{1,2}$. The pictorial representation of ill-effect of lead on human health is shown in Fig.1.

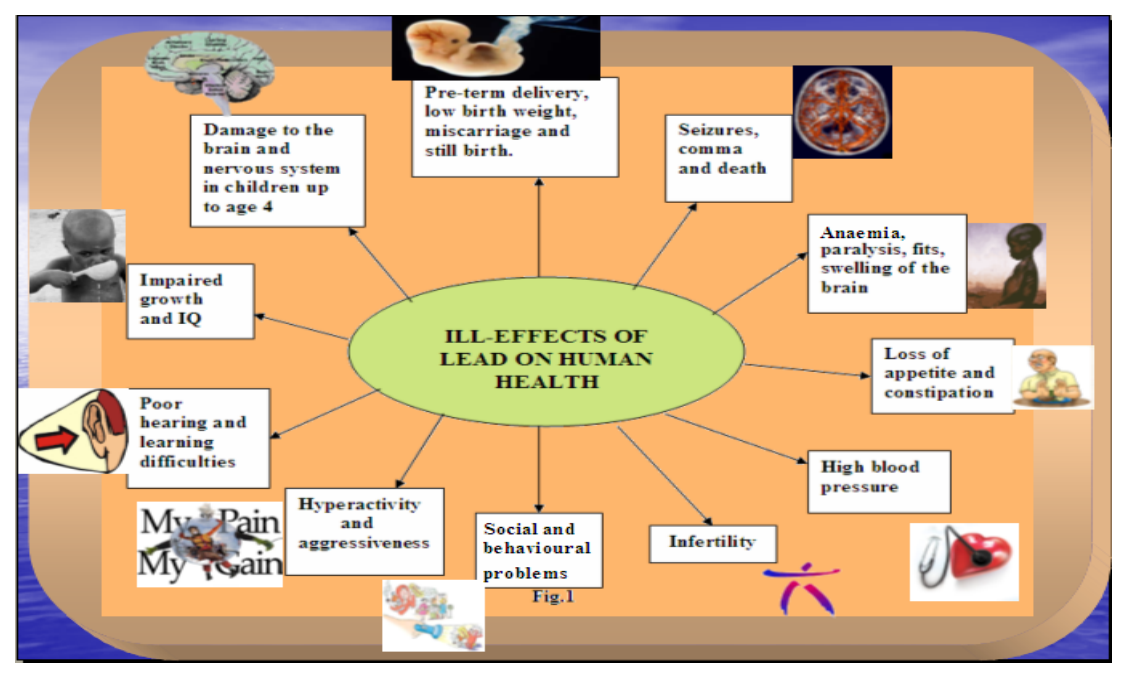

For the above reasons worldwide interest in prevention of lead poisoning has received particular attention and led to extensive surveys in many countries. In this context, a systematic study of lead content in various medicinal samples (Fig.2) is considered worthwhile as lead may be loaded in small but appreciable quantities in medicines due to contamination during packaging through soldering, addition of lead compounds as colouring agent and preservatives etc.

Medicines are lifeline of mankind for the treatment of various ailments. The most widespread ailments are cold, cough and body aches for which people generally go for ayurvedic and homeopathy medicines especially in case of children and infants. 


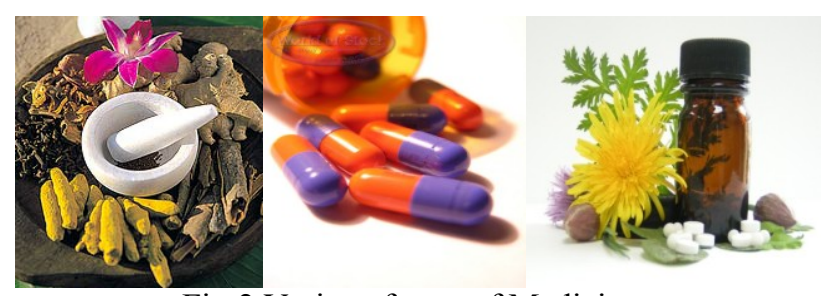

Fig.2 Various forms of Medicines

Ayurveda is a system of traditional medicine native to India, and practiced in other parts of the world as a form of alternative medicine $e^{4}$. It is considered to be a form of complementary and alternative medicine (CAM) within the western world, where several of its methods - such as herbs, massage, and Yoga as exercise or alternative medicine - are applied on their own as a form of CAM treatment. Some examples are Dasamool, Rubzon, Natpoll, Joshina, Kasamrita, Branchozen syrup, Arthozen, Anand Bhairav Ras, Vyoshadi Bati, Tribhuvan Kriti Rasa, Mahamash Tail etc.

Homeopathy was invented by the German physician Samuel Hahnemann (1755-1843) in the late 18th and early 19th centuries ${ }^{5}$. The system is based on the idea that substances that produce symptoms of sickness in healthy people will have a curative effect when given in very dilute quantities to sick people who exhibit those same symptoms. Homeopathic remedies are believed to stimulate the body's own healing processes. Some examples are Bella Donna, Rhus Tox, Similia, , Pulmoclen, Coldmed, Koffmed, AF-200, AF - Pyrexia, Cold Sinus etc.

About 20 medicinal samples of various categories have been collected and estimation of lead content was done by Graphite Furnace Atomic Absorption Spectrophotometry (GFAAS) method followed by comparative study. Our result shows unusually high lead content in some ayurvedic and homeopathic medicines ranging from $10 \mathrm{ppm}$ to $3000 \mathrm{ppm}$. So, we feel it proper to advise the clinicians and consumers in case there are others who may be unknowingly affected by types of medications prescribed in Ayurvedic and Homeopathic medicines.

\subsection{Materials}

\section{Materials and Methods}

Various samples of medicines in packed and sealed containers were collected from different parts of Karnataka such as Bellary, Raichur, Mysore, Hubli and Bangalore, polyethylene bottles of equal volume for sampling (washed thoroughly with $30 \% \mathrm{~V} / \mathrm{V} \mathrm{HCl}$ followed by $30 \% \mathrm{~V} / \mathrm{V}$ Nitric acid, then rinsed with distilled water and dried).

\subsection{Methodology}

Experimental: Analysis of lead content in various samples by Atomic Absorption Method (Graphite Furnace Atomic Absorption Spectroscopy) ${ }^{3}$.

\subsection{Description and Working of Atomic Absorption Spectrophotometer}

Atomic absorption spectrophotometry provides accurate quantitative analyses for metals in water, sediments, soils or rocks. (Samples are analyzed in solution form, so solid samples must be leached or dissolved prior to analysis.)

Atomic absorption spectrophotometer (Perkin Elmer 30303B) has four basic parts: interchangeable lamps that emit light with element-specific wavelengths, a sample aspirator, a flame or furnace apparatus for volatilizing the sample, and a photon detector (Fig.3). In order to analyze for any given element, a lamp is chosen that produces a wavelength of light that is absorbed by that element. Sample solutions are aspirated into the flame. If any ions of the given element are present in the flame, they will absorb light produced by the lamp before it reaches the detector. The amount of light absorbed depends on the amount of the element present in the sample. Absorbance values for unknown samples are compared to calibration curves prepared by running known samples.

\subsection{Instrument Statistics}

The system is a microprocessor-controlled double beam spectrophotometer with a graphite furnace attachment for flameless analysis. Both acetylene and nitrous oxide fuel mixtures can be used to allow for the analysis of a wide range of elements. 


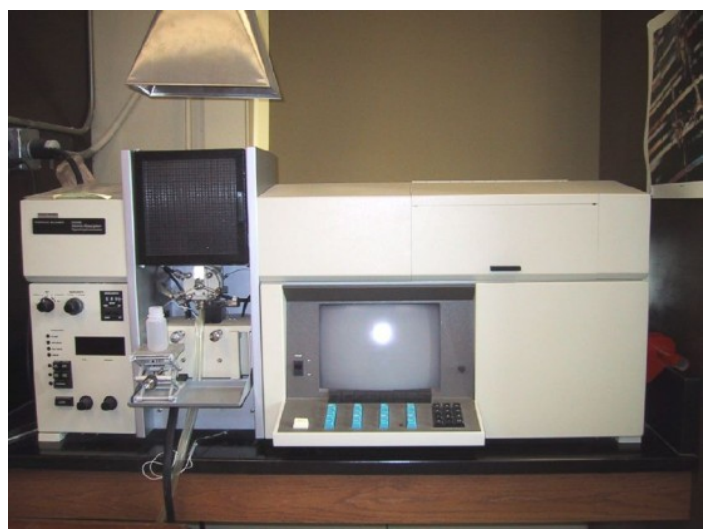

Perkin Elmer 30303B Atomic Absorption Spectrophotometer

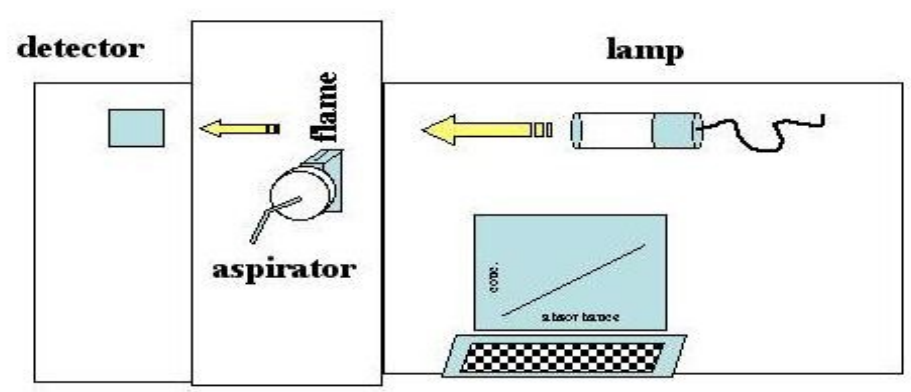

Fig. 3

\section{Result}

The investigations of lead content in various medicinal samples were done under two different categories as mentioned below:

\section{MEDICINE}

(Commonly used for cold, cough \& body aches)

\section{AYURVEDIC}

11 samples were analyzed (Table 1 and Graph I)

\section{HOMEOPATHIC}

09 samples were analyzed (Table 2 and Graph II)

Table 1: Lead content in Ayurvedic medicinal samples used for cold, cough and body aches

\begin{tabular}{|c|c|c|c|}
\hline S. No. & Sample Particulars & \multicolumn{2}{|c|}{ Lead Concentration } \\
\cline { 3 - 4 } & & $\left.\mathbf{( p p m}^{\mathbf{a}}\right)$ & 20,000 \\
\hline 1. & Dasamool-Sample-1A & 20 & $<4(\mathrm{BDL})$ \\
\hline 2. & Rubzon-Sample-2A & $<0.004\left(\mathrm{BDL}^{*}\right)$ & $<4(\mathrm{BDL})$ \\
\hline 3. & Natpoll Tablets-Sample-3A & $<0.004(\mathrm{BDL})$ & $<4(\mathrm{BDL})$ \\
\hline 4. & Joshina Formula-Sample-4A & $<0.004(\mathrm{BDL})$ & $<4(\mathrm{BDL})$ \\
\hline 5. & Kasamrita-Sample-5A & 20 & 20,000 \\
\hline 6. & Branchozen syrup-Sample-6A & 3000 & $30,00,000$ \\
\hline 7. & Arthozen capsule-Sample-7A & 200 & $2,00,000$ \\
\hline 8. & Anand Bhairav Ras (Jwar)-Sample-8A & 100 & $1,00,000$ \\
\hline 9. & Vyoshadi Bati-Sample-9A & 100 & $1,00,000$ \\
\hline 10. & Tribhuvan Kriti Rasa-Sample-10A & 50 & 50,000 \\
\hline 11. & Mahamashtail-Sample-11A & . & \\
\hline
\end{tabular}

[Note: * BDL: Below Detection Limit; a: parts per million; b: parts per billion] 


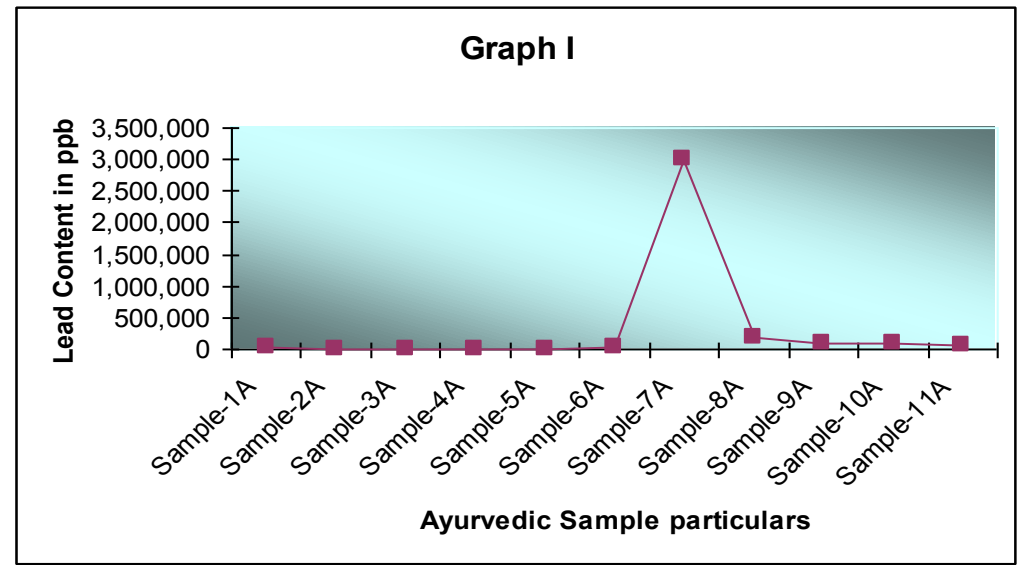

Table 2: Lead content in Homeopathic medicinal samples used for cold, cough and body aches

\begin{tabular}{|c|c|c|c|}
\hline S. No. & Sample Particulars & \multicolumn{2}{|c|}{ Lead Concentration } \\
\cline { 3 - 4 } & & $\left(\mathbf{p p m}^{\mathbf{a}}\right)$ & 10 \\
\hline 1. & Bella Donna-Sample-H1 & $<0.004\left(\mathrm{BDL}^{*}\right)$ & 10,000 \\
\hline 2. & Rhus Tox-Sample-H2 & $<4(\mathrm{BDL})$ \\
\hline 3. & Similia-Sample-H3 & $<0.004(\mathrm{BDL})$ & $<4(\mathrm{BDL})$ \\
\hline 4. & Pulmoclen-Sample-H4 & 80 & 80,000 \\
\hline 5. & Coldmed-Sample-H5 & $<0.004(\mathrm{BDL})$ & $<4(\mathrm{BDL})$ \\
\hline 6. & Koffmed-Sample-H6 & 10 & 20,000 \\
\hline 7. & AF-200-Sample-H7 & 20 & 10,000 \\
\hline 8. & AF-Pyrexia-Sample-H8 & 10 & 10,000 \\
\hline 9. & Cold Sinus-Sample-H9 & 10 & 1000 \\
\hline
\end{tabular}

[Note: * BDL: Below Detection Limit; a: parts per million; b: parts per billion]

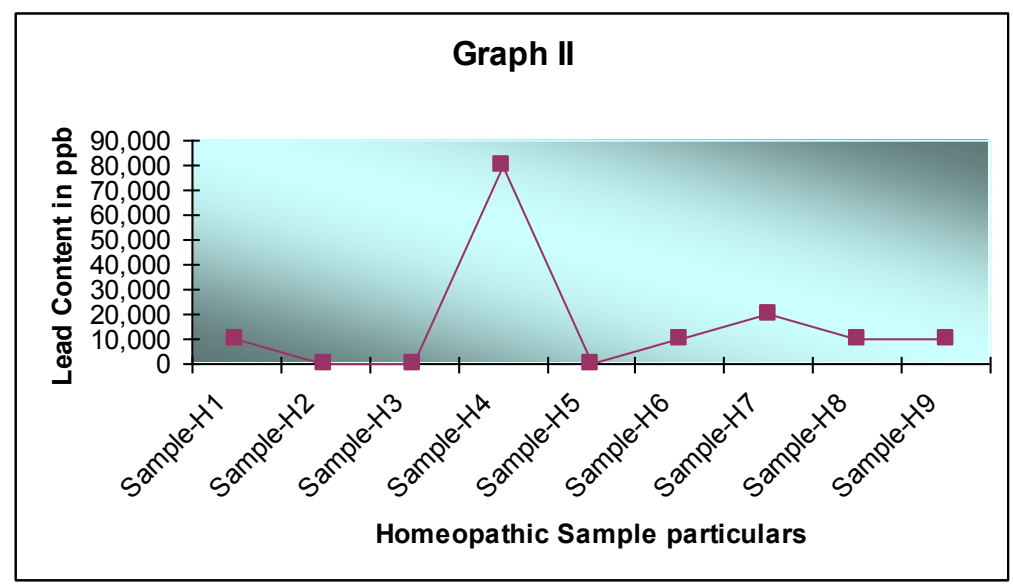

\section{Discussion}

It is evident from the Table 1 that the lead content in ayurvedic sample 7A (Arthozen capsule) is undesirably high 30,00,000 ppb showing maximum among all the samples analyzed. Dasamool, Branchozen, Anand Bhairav Ras, Vyoshadi Bati and Tribhuvan Kriti Rasa also show the significant lead content.

The data of Table 2 proves that Pulmoclen has highest lead content among all the homeopathy medicinal samples analyzed showing the value of $80,000 \mathrm{ppb}$. The other six samples show the significant lead content ranging from 10,000 to $20,000 \mathrm{ppb}$.

The relatively high lead contamination of ayurvedic and homeopathic medicinal samples reported here may be due to:

(๑) plants and their extracts used for preparing the medicines contaminated by lead through soil, water and air etc.

(๑) during packaging process such as soldering

(?) addition of colour content as lead compounds

(-) addition of lead compounds as preservatives 


\section{Conclusion}

Category Total No. of No. of samples having Lead No. of Samples having Samples below detection limit

Ayurvedic $\quad 11$

4

Homeopathy 09

high Lead content

7

6

The result shows unusually high lead content in some ayurvedic medicines ranging from $20 \mathrm{ppm}$ to $3000 \mathrm{ppm}$ and in some homeopathy medicines ranging from $10 \mathrm{ppm}$ to $80 \mathrm{ppm}$.

So, we feel it proper to advise the clinicians and consumers who may be unknowingly affected by types of medications prescribed in these medicines.

\section{Acknowledgement}

I express my profound sense of gratitude to Dr. Thuppil Venkatesh, Director of National Referral Centre for Lead Poisoning in India (NRCLPI), Advisor of Quality Council of India (QCI), Professor, Dept. of Biochemistry, St. John's National Academy of Health Sciences, Bangalore and his worthy team for awarding this short term research project.

I extend my sincere thanks to my head of the institution for her moral support throughout the project, colleague Mrs. Mary Arpana and the students of III B.Sc. for their active participation in sample collections from different parts of Karnataka.

\section{References}

[1] http://www.hc-sc.gc.ca/hl-vs-iyh-vsv/environ/lead-plomb-eng.php

[2] http://www.netdoctor.co.uk/ate/growthandmetabolism/202821.html

[3] http://en.wikipedia.org/wiki/Graphite_furnace_atomic_absorption

[4] http://en.wikipedia.org/wiki/Ayurvrda

[5] http://en.wikipedia.org/wiki/Homeopathy 